Article

\title{
Regenerative Biotechnologies in Plastic Surgery: A Multicentric, Retrospective, Case-Series Study on the Use of Micro-Needling with Low-Level Light/Laser Therapy as a Hair Growth Boost in Patients Affected by Androgenetic Alopecia
}

\author{
Pietro Gentile ${ }^{1, *(1)}$, Simone Garcovich ${ }^{2}$, Soo-Ik Lee ${ }^{3}$ and Sangbum Han ${ }^{4, *}$ \\ 1 Department of Surgical Sciences, “Tor Vergata” University, 00173 Rome, Italy \\ 2 Institute of Dermatology, F. Policlinico Gemelli IRCSS, Università Cattolica del Sacro Cuore, 00168 Rome, Italy; \\ simgarko@yahoo.it \\ 3 New Hair Institute Korea, Seoul 02435, Korea; newhairdg2022@gmail.com \\ 4 Department of Bioconvergence, College of Health Sciences, Kyungnam University, Changwon 51767, Korea \\ * Correspondence: pietrogentile2004@libero.it (P.G.); sangbum@kyungnam.ac.kr (S.H.); \\ Tel.: +39-3388515479 (P.G.); +82-552496336 (S.H.)
}

\section{check for}

updates

Citation: Gentile, P.; Garcovich, S.; Lee, S.-I.; Han, S. Regenerative

Biotechnologies in Plastic Surgery: A

Multicentric, Retrospective,

Case-Series Study on the Use of

Micro-Needling with Low-Level

Light/Laser Therapy as a Hair

Growth Boost in Patients Affected by

Androgenetic Alopecia. Appl. Sci.

2022, 12, 217. https://doi.org/

10.3390/app12010217

Academic Editor: Rossella Bedini

Received: 3 November 2021

Accepted: 23 December 2021

Published: 27 December 2021

Publisher's Note: MDPI stays neutral with regard to jurisdictional claims in published maps and institutional affiliations.

Copyright: (c) 2021 by the authors Licensee MDPI, Basel, Switzerland. This article is an open access article distributed under the terms and conditions of the Creative Commons Attribution (CC BY) license (https:// creativecommons.org/licenses/by/ $4.0 /)$.

\begin{abstract}
A new biotechnology based on micro-needling (MND) with low-level light/laser therapy (LLLT) that is used for hair re-growth (HR-G) needs to be standardized. The study aims to report the clinical outcomes resulting from a multicentric, retrospective, observational, case-series study in which MND with LLLT was used on patients affected by androgenic alopecia (AGA). Twenty-six patients were initially enrolled of which 15 males were classified as stages I-III of vertex by the Norwood-Hamilton scale, and 11 females was classified in stages I-II by the Ludwig scale. Twenty patients (10 females and 10 males) were analyzed after their screening (the exclusion and inclusion criteria evaluation). The HR-G assessment was evaluated with photography, as well as the physician's and patient's global assessment scales, in addition to standardized phototrichograms, during a short follow-up at T0-baseline, T1-16 weeks. Encouraging results represented by a hair density increase of $12 \pm 2$ hairs $/ \mathrm{cm}^{2}$ at T1 after 16 weeks (16 weeks vs. 0 weeks) in the targeted area, compared with the baseline results ( $59 \pm 2$ hairs $/ \mathrm{cm}^{2}$ at $\mathrm{T} 1$ versus $47 \pm 2$ hairs $/ \mathrm{cm}^{2}$ at baseline), were observed using computerized trichograms with a statistically significant difference in hair re-growth $(p=0.0238)$. The effectiveness of MND with LLLT use has been demonstrated in mild to moderate AGA patients.
\end{abstract}

Keywords: hair re-growth LLLT; low-level led therapy; LLLT therapy; micro-needling in hair loss; micro-needling and low level led therapy in hair loss; regenerative plastic surgery; plastic surgery

\section{Introduction}

Scientific research in the regenerative field exists even for the development of miniinvasive biotechnologies aimed to enhance hair re-growth (HR-G) in patients suffering from androgenetic alopecia (AGA). AGA is one of the most important and frequent hair loss (HL) causes affecting a mean of $80 \%$ of white men and $40 \%$ of women, determining, respectively, a male pattern hair loss (MPHL) and a female pattern hair loss (FPHL) [1-4].

The number of papers evaluating the effectiveness of low-level light/laser therapy (LLLT) in MPHL and/or FPHL has exponentially increased during the last decade (2011-2021).

The first research on "photo-bio-stimulation", or LLLT, was performed in 1967 on mice by using the ruby laser [5]. The purposed mechanism of LLLT in HR-G is the stimulation of mitochondria located in the hair bulge stem cells. Cytochrome c-oxidase (CCO,) in the membrane of mitochondria, is the target chromophore of red light that leads to mitochondrial respiration. Reactive oxygen species (ROS) and adenosine triphosphate (ATP) then stimulate cellular proliferation, migration, and oxygenation, which, consequently, promotes 
hair growth [6]. In 2007, the first cleared LLLT device was introduced for MPHL by the US Food and Drug Administration (FDA) [7]. Up until the present, LLLT technology, based on the laser diode (LD) and light emitting diode (LED), has been adopted by different manufacturers to create LLLT devices; nevertheless, only some of the LLLT products are cleared by the FDA, with few articles published to support the efficacies.

Red light and laser therapies at $660 \mathrm{~nm}$ have been confirmed as an effective treatment for HL, and, therefore, the use of LLLT, such as phototherapy with LED, [8] has been intensified to market HG in AGA $[9,10]$. For several years, LED phototherapy has been offered as a good and safe device for the treatment of the skin, mucous, and scalp affected by inflammatory components, being employed efficaciously within the treatment of acne [11], vaginal atrophy [12], facial aging [13,14], and, additionally, in disorders associated with HL [15]. The innovative use of combining LLLT, LED, and magnetic flux technology for the treatment of AGA seems to be the latest advancement. The synergy of emissions, including the spectrum, infrared, a soft laser, and magnetic flux helps to increase the density of the hair by activating the cellular metabolism of the hair follicles (HFs) and improving the standard and density of the prevailing hair.

Additionally, the combined use of the micro-needling (MND) technique with LLLT has further improved HR-G in patients with AGA [16].

This study aims to describe the impact of LLLT with MND on HR-G. The characteristics and, therefore, the outcomes of the device analyzed are reported, aspiring to clarify any doubts regarding the chance to standardize the utilization of this method.

\section{Materials and Methods}

\subsection{Study Overview}

This multicentric, retrospective, observational case-series study has been performed following the principles reported in the Declaration of Helsinki and the internationally consented ethics in clinical research [17]. A high-quality assessment was carried out based on the Strengthening the Reporting of Observational Studies in Epidemiology (STROBE) checklist [18]. All patients received, understood, and signed detailed informed consent forms before any study procedure, which included information about the protocol, including the risks, benefits, and alternative therapies.

The collected data has been independently analyzed in Korea by Prof. Han (Department of Bioconvergence, College of Health Sciences, Kyungnam University, Gyeongsangnamdo, South Korea), and Dr. Soo-Ik Lee (New Hair Institute Korea, Seoul, Korea) while in Italy, the data was analyzed by Prof Gentile (Surgical Science Department, University of "Tor Vergata", Rome, Italy) and Dr. Garcovich (Institute of Dermatology, F. Policlinico Gemelli IRCSS, Università Cattolica del Sacro Cuore, Rome).

This paper has been the object of a research contract between the author, P.G., and the “Tor Vergata" University, approved by Rectoral Decree R.D n. \#1467/2017, and is continued in the associate professor contract \#13489/2021.

\subsection{Data Extraction}

Data regarding the treatment kind and the outcomes were independently collected by the four authors, screened, and finally identified as eligible data according to the inclusion and exclusion criteria evaluation. Any disagreement on the extracted data was settled by a consensus among P.G. and S.H. Information on the patients (age, sex, race, comorbidities), interventions (use of topical drugs such as minoxidil, finasteride, platelet-rich plasma, or retinoids), and the follow-up (16 weeks) was gathered by the authors (P.G. and S.H).

Data on hair density, session frequency (days/week), treatment duration (weeks), and patients' clinical results were collected.

In terms of outcomes, the type of measurement was described (unit area trichograms, photo-trichograms, global photography, direct hair count, hair analysis software, and investigator hair analysis), as well as the primary endpoints (hair density, hair thickness/shaft diameter, vellus hair count/density, terminal hair count/density, anagen percentage, telo- 
gen percentage, tensile strength, and investigator global assessment), and the secondary endpoints (patient satisfaction and subject global assessment).

\subsection{Endpoint Definition}

The differences in hair density (HD) between the baseline (T0) and the LLLT treatments at 16 weeks (T1), evaluated with instrumental trichoscopy, were the primary outcome. The $p$-value indicated LLLT as being an effective treatment option when compared to the baseline.

Clinical outcomes were analyzed through objective and subjective evaluations. The objective evaluation was performed by the investigators, while the subjective evaluation was performed by the patients. The investigators' evaluation was based on the analysis of clinical and global pictures, applying a scale of six degrees (excellent, good, discreet, enough, poor, or inadequate). The patient self-evaluation was performed applying the same six degrees previously reported. The factors/variables that were also considered during outcomes analysis were itchiness, slight redness, slight numbness of the treated area, and headaches.

\subsection{Low-Level Light/Laser Therapy (LLLT) Protocols and Devices}

LLLT protocols, in this study, were represented by two treatments weekly for four months with one vial of hair solution (HR3 Matrix Hair Solution Alpha ${ }^{\circledR}$-DTS MG Co., Ltd., Seoul, Korea, \#B108-147) penetrated using the Hairgen Booster ${ }^{\circledR}$ device (DTS MG Co., Ltd., Seoul, Korea, \#B108-147) through hair micro-needling stamps (HR3 Matrix Hair Stamp ${ }^{\circledR}$-DTS MG Co., Ltd., Seoul, Korea, \#B108-147) (Figure 1A). The participation period for every patient was three months, including the screening/baseline/first treatment visit until the last follow-up visit at four months. The whole treatment course included 32 sessions of employing a home LLLT device (Figure 1A) conducted twice per week for 16 weeks (wks) (T1). Patients were re-evaluated at four months (T1-16 wks) (four months after the first treatment session). The Hairgen Booster ${ }^{\circledR}$ was applied and passed over the targeted area, maintaining the same distance between the scalp and the LEDs, permitting, contextually, the sterile infiltration $(0.22 \mu \mathrm{m})$ by the MND stamp of the solution (HR3 Matrix Hair Solution Alpha ${ }^{\circledR}$-Repilosome-EPH1) containing the human growth hormone (GH), epidermal growth factors (EGF), vasoactive intestinal peptide (VIP), several polypeptides (sh-Polypeptide-7, sh-Oligopeptide-1, sh-Polypeptide-71), glycerin, lecithin, polysorbate 60 , sodium citrate, citric acid, phenoxyethanol, and water (Figure 1B). The accuracy of the procedure, however, depended on the use of one's hands and on how the device was passed over the scalp.

The Hairgen Booster ${ }^{\circledR}$ is constituted by lights with various wavelengths ranging from $423 \mathrm{~nm}$ to $640 \mathrm{~nm}$. Two colors of lights (red and blue) (Figure 1C,D) that emit an output of less than $1 \mathrm{~W}$ (low-level LED light) were used:

- Blue light (Figure 1C), with a wavelength of $423 \mathrm{~nm}$ and a skin penetration depth of $1 \mathrm{~mm}$, activates the keratin present in the hair shaft, increases the water retention of hair, acts in the microbiological control, and diminishes the sebaceous gland, reducing the grease of the scalp;

- $\quad$ Red light (Figure 1D), with a wavelength of $640 \mathrm{~nm}$ and a skin penetration depth of 1-6 mm, promotes cell metabolism, improves blood circulation, promotes nutrition supplies to capillaries, strengthens hair strands, promotes the alignment of the cuticles, and promotes pain relief.

Additionally, the device offers scalp massaging and heating functions to improve blood flow and provide more nutrients and oxygen to the HFs.

All the patients affirmed, in a declaration signed during the follow-up, that they respected the use of the recommendations of the device during homecare. 


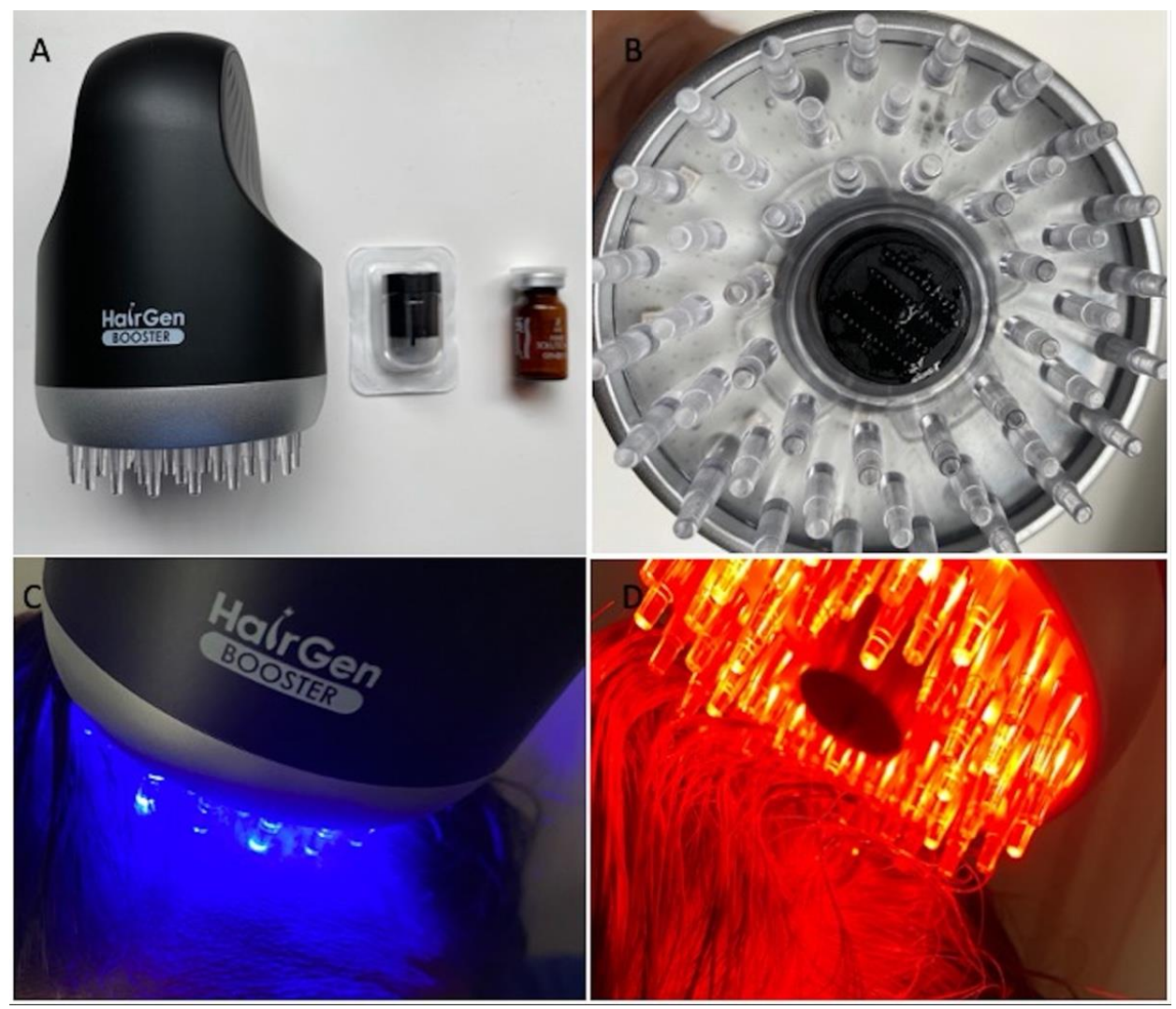

Figure 1. MND and LLLT protocol (A) Hairgen Booster ${ }^{\circledR}$ (DTS MG Co., Ltd., Seoul, Korea, \#B108-147) device with HR3 Matrix Hair Solution Alpha ${ }^{\circledR}$ (DTS MG Co., Ltd., Seoul, Korea, \#B108-147) and HR3 Matrix Hair Stamp ${ }^{\circledR}$ (DTS MG Co., Ltd., Seoul, Korea, \#B108-147); (B) detail of HR3 Matrix Hair Stamp ${ }^{\circledR}$ inserted into the Hairgen Booster ${ }^{\circledR} ;(\mathbf{C})$ blue light application (wavelength $423 \mathrm{~nm}$ ) during the treatment; (D) red Light application (wavelength $640 \mathrm{~nm}$ ) during the treatment.

\subsection{Patients}

This multicentric study was performed initially involving 26 patients that were treated since January 2020, aged 20-71 years. The 15 males were classified as in stages I-III of vertex by the Norwood-Hamilton scale, and the 11 females were classified as in stages I-II by the Ludwig scale.

Patient characteristics are reported in Table 1.

The assessment of HR-G was evaluated with photography, as well as the physician's and patient's global assessment scales and standardized phototrichograms during the follow-up: T0-baseline, T1-16 weeks. The exclusion criteria were divided into two types, local and general. General exclusion criteria included the use of pharmacological therapeutics targeting AGA (Finasteride ${ }^{\circledR}$, similar drugs, and/or anti-androgens) within the previous year, as well as anticoagulation use and chronic dermatologic conditions such as eczema, psoriasis, infections of the scalp, a history of poor wound healing or keloid formation, and a history of thyroid dysfunction and/or autoimmune disorders. Local exclusion criteria included an MPHL, a vertex degree of over III, an FPHL degree of over II, and the use of topical medicines for AGA (lotions such as Minoxidil ${ }^{\circledR}$, prostaglandin analogs, retinoids, or corticosteroids) within the previous year.

Of the 26 patients initially enrolled, 5 males and 1 female were excluded, as they only later revealed that they continued to apply lotions such as Minoxidil ${ }^{\circledR}$ to the scalp. 
Table 1. Patient characteristics.

\begin{tabular}{|c|c|c|c|c|c|c|}
\hline Patients & Gender & $\begin{array}{l}\text { Norwood- } \\
\text { Hamilton } \\
\text { Degree }\end{array}$ & $\begin{array}{l}\text { Ludwig } \\
\text { Degree }\end{array}$ & Targeted Area & Age & Race \\
\hline 1 & Male & III-vertex & - & $\begin{array}{c}\text { Frontal, } \\
\text { temporal, } \\
\text { parietal, vertex }\end{array}$ & 49 & Caucasian \\
\hline 2 & Male & III-vertex & - & $\begin{array}{c}\text { Frontal, } \\
\text { temporal, } \\
\text { parietal, vertex }\end{array}$ & 31 & Asian \\
\hline 3 & Male & III-vertex & - & $\begin{array}{c}\text { Frontal, } \\
\text { temporal, } \\
\text { parietal, vertex }\end{array}$ & 61 & Caucasian \\
\hline 4 & Male & II & - & $\begin{array}{c}\text { Frontal, } \\
\text { temporal }\end{array}$ & 26 & Asian \\
\hline 5 & Male & III-vertex & - & $\begin{array}{c}\text { Frontal, } \\
\text { temporal, } \\
\text { parietal, vertex }\end{array}$ & 71 & Caucasian \\
\hline 6 & Male & III-vertex & - & $\begin{array}{c}\text { Frontal, } \\
\text { temporal, } \\
\text { parietal, vertex }\end{array}$ & 56 & Asian \\
\hline 7 & Male & IIa & - & $\begin{array}{l}\text { Frontal, } \\
\text { temporal, } \\
\text { parietal }\end{array}$ & 45 & Caucasian \\
\hline 8 & Male & III-vertex & - & $\begin{array}{c}\text { Frontal, } \\
\text { temporal, } \\
\text { parietal, vertex }\end{array}$ & 29 & Asian \\
\hline 9 & Male & II & - & $\begin{array}{l}\text { Frontal, } \\
\text { temporal, } \\
\text { parietal }\end{array}$ & 35 & Caucasian \\
\hline 10 & Male & I & - & Frontal & 20 & Asian \\
\hline 11 & Female & - & I & Frontal, parietal & 40 & Caucasian \\
\hline 12 & Female & - & II & $\begin{array}{c}\text { Frontal, } \\
\text { temporal, } \\
\text { parietal }\end{array}$ & 60 & Asian \\
\hline 13 & Female & - & II & $\begin{array}{c}\text { Frontal, } \\
\text { temporal, } \\
\text { parietal, vertex }\end{array}$ & 63 & Caucasian \\
\hline 14 & Female & - & II & $\begin{array}{c}\text { Frontal, } \\
\text { temporal, } \\
\text { parietal, vertex }\end{array}$ & 40 & Asian \\
\hline 15 & Female & - & II & $\begin{array}{c}\text { Frontal, } \\
\text { temporal, } \\
\text { parietal, vertex }\end{array}$ & 55 & Caucasian \\
\hline 16 & Female & - & II & $\begin{array}{l}\text { Frontal, } \\
\text { temporal, } \\
\text { parietal }\end{array}$ & 39 & Asian \\
\hline 17 & Female & - & II & $\begin{array}{c}\text { Frontal, } \\
\text { temporal, } \\
\text { parietal, vertex }\end{array}$ & 61 & Caucasian \\
\hline 18 & Female & - & II & $\begin{array}{l}\text { Frontal, } \\
\text { temporal, } \\
\text { parietal }\end{array}$ & 26 & Asian \\
\hline 19 & Female & - & I & Frontal, parietal & 38 & Caucasian \\
\hline 20 & Female & - & I & Frontal, parietal & 25 & Asian \\
\hline
\end{tabular}


Twenty patients (10 females, including 5 Caucasians and 5 Asians (Figure 2A) and 10 males, including 5 Asians (Figure 3A) and 5 Caucasians (Figures 4A and 5A)) were included in the study and were analyzed.

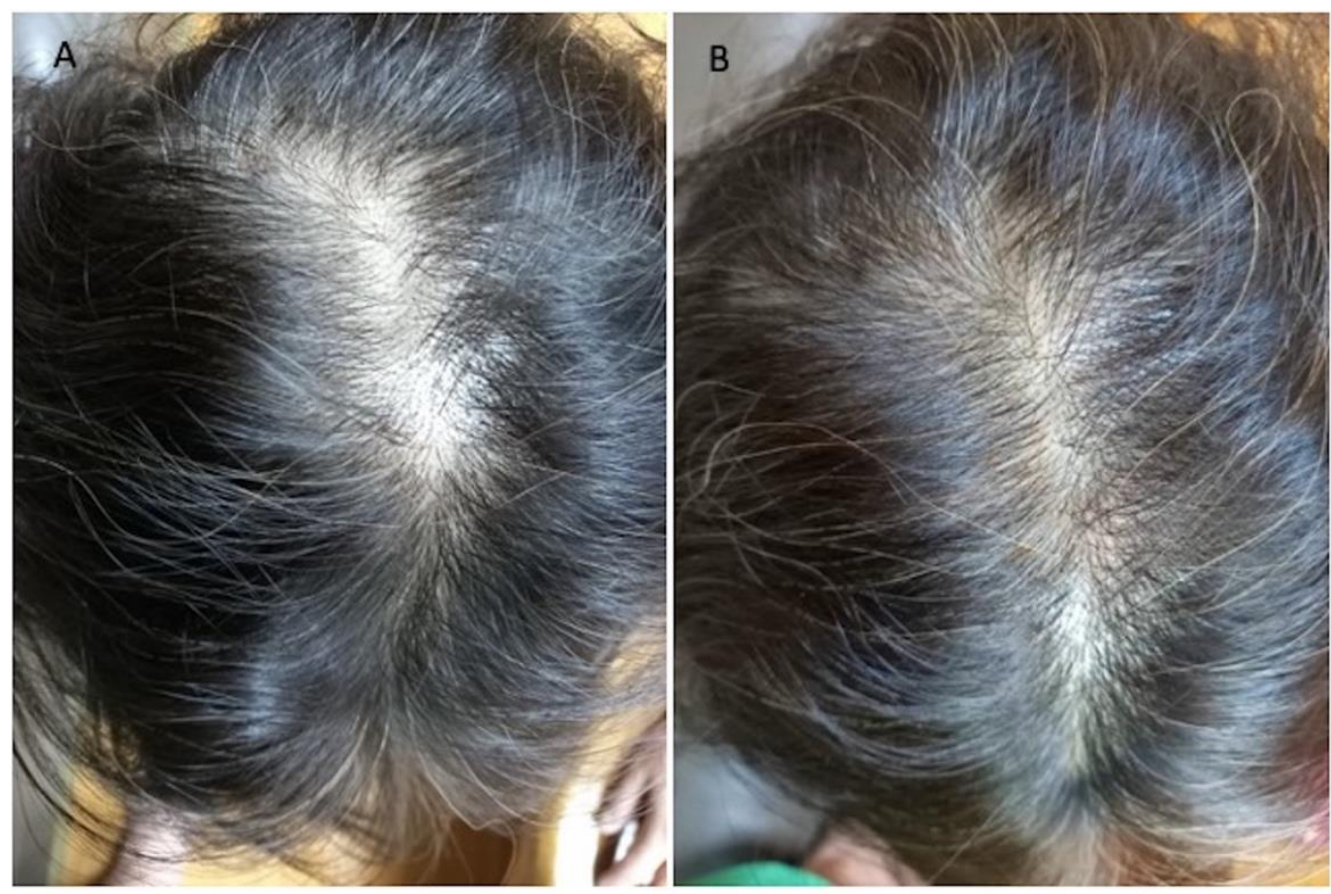

Figure 2. Asian female patients treated with MND and LLLT protocols. (A) Pre-operative view of the scalp of a 60-year-old female patient affected by AGA II according to Ludwig scale with hair loss localized in the frontal, temporal, and parietal area; (B) post-operative view at T1-16 wks after MND and LLLT treatment with detail of HR-G in parietal area.
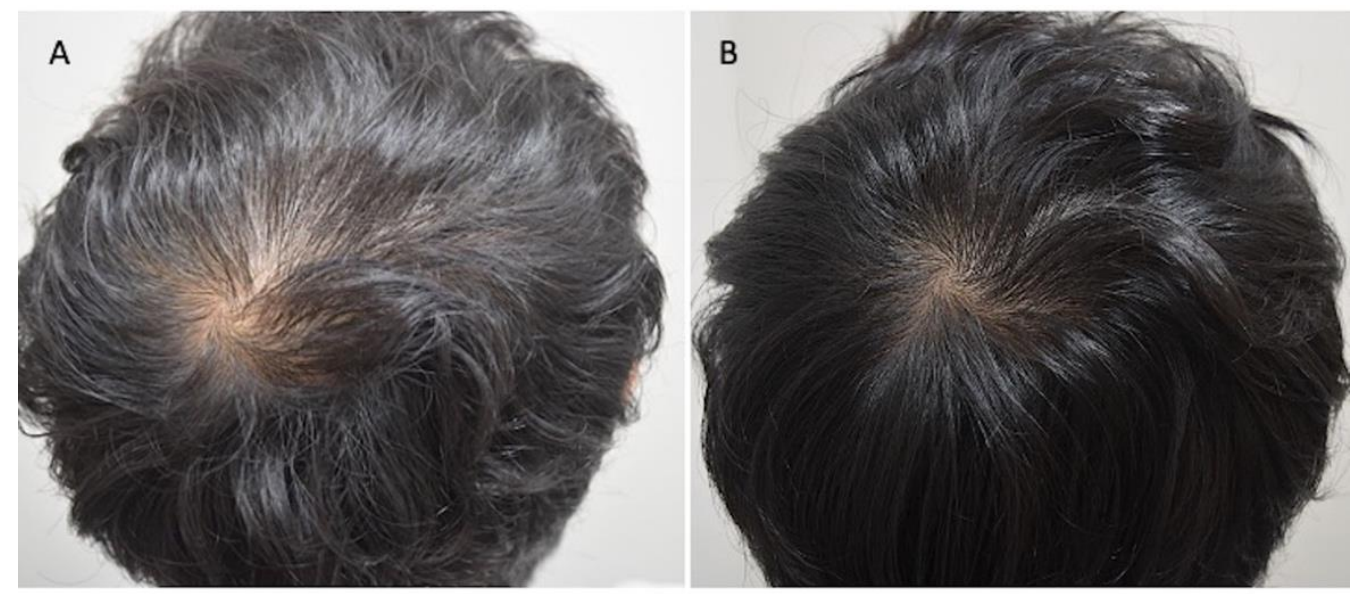

Figure 3. Asian male patients treated with MND and LLLT protocols. (A) Pre-operative view of the scalp of a 29-year-old male patient affected by AGA III-vertex according to Norwood-Hamilton scale with hair loss localized in the frontal, temporal, parietal, and vertex area; (B) post-operative view at T1-16 wks after MND and LLLT treatment with detail of HR-G in vertex area. 


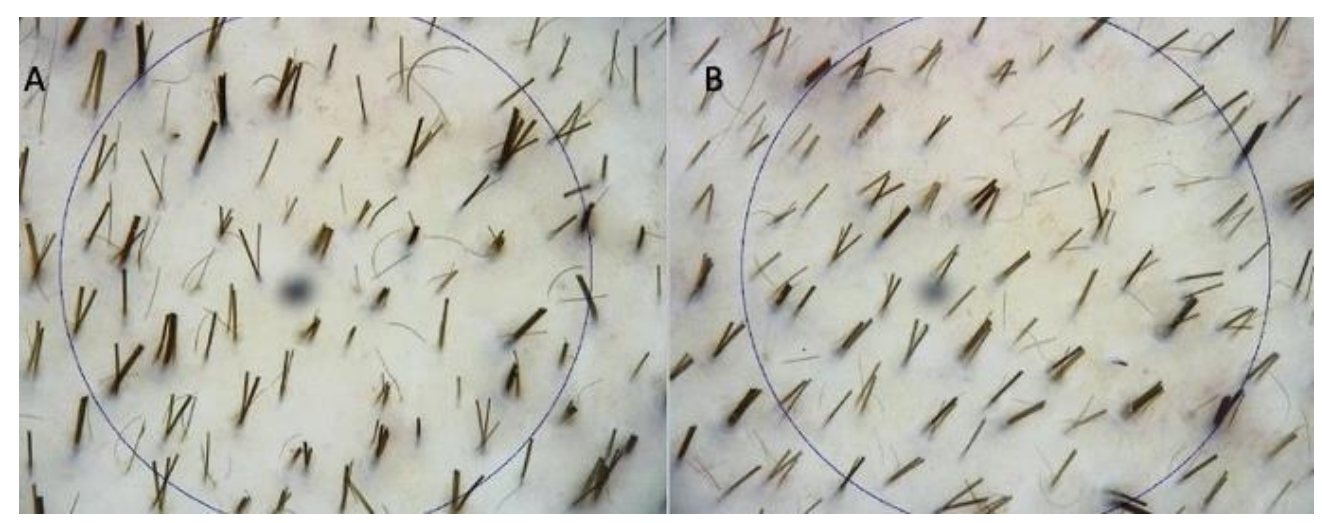

Figure 4. TrichoScan digital image analysis performed by Fotofinder in a patient is shown in Figure 5. (A) At T0 pre-operative hair density was $63 \pm 2$ hairs $/ \mathrm{cm}^{2}$ and proportions of telogen and anagen hairs were $36.1 \%$ and $55.6 \%$, respectively; (B) at T1-16 wks post-operative hair density was $80 \pm 2$ hairs $/ \mathrm{cm}^{2}$, and proportions of telogen and anagen hairs were $44.7 \%$ and $51.3 \%$, respectively.

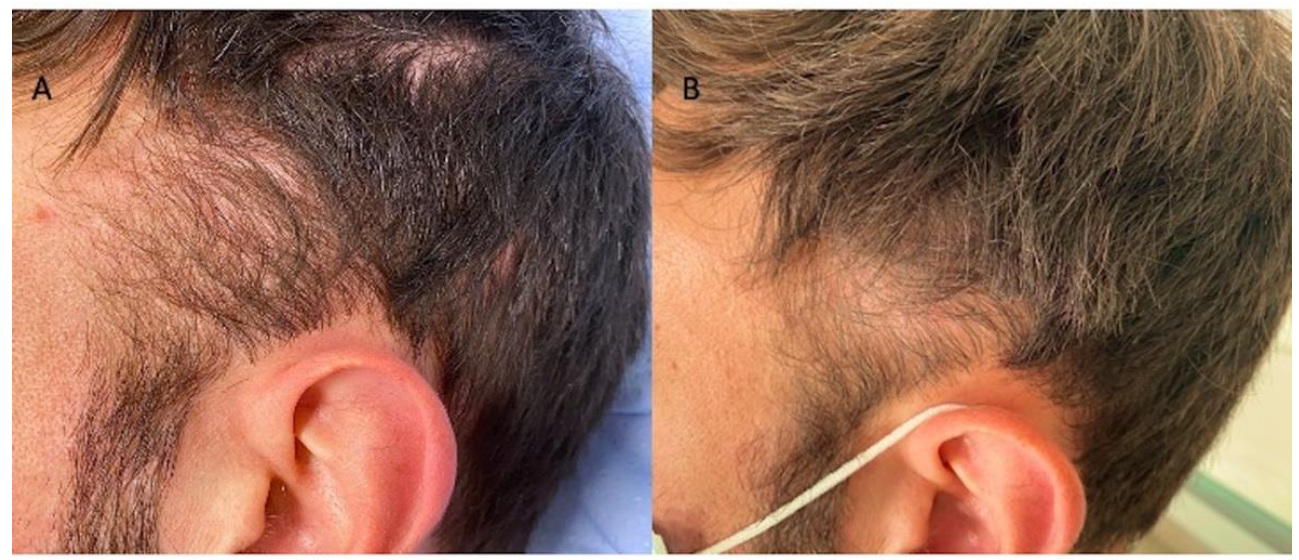

Figure 5. Caucasian male patients were treated with MND and LLLT protocols. (A) Pre-operative view of the scalp of 35-year-old male patient affected by AGA II according to Norwood-Hamilton scale with hair loss localized in the frontal, temporal, and parietal area; (B) post-operative view at T1-16 wks after MND and LLLT treatment with detail of HR-G in the temporal area.

\subsection{The Risk Mitigation Measures}

The risk evaluation and mitigation strategies (REMSs) with elements to assure safe use (ETASU) have been used for the LLLT procedures, performed in two different countries, with a significant safety risk reduction. ETASU characteristics were represented by the adoption of the same applicative protocol for all patients, the identification of exclusion and inclusion criteria, and the use of the medical devices with CE marks. All risks were identified before the clinical treatments. Ineffective results were the most frequent risk. Most REMSs required the training of healthcare providers and the suitable evaluation of the selected patients.

The main rationale for ETASU was to provide patients with safe access to the procedures. The authors evaluated the individual characteristics of REMSs with ETASU by searching the FDA website (http:/ / www.accessdata.fda.gov/scripts/cder/rems/index. $\mathrm{cfm}$, accessed on 1 July 2021) and specifically identified them in: 
- $\quad$ The informed consent for all patients, where the risks (represented only by ineffective results) and side effects of the procedures were reported;

- A specific training plan to healthcare providers;

- A communications plan of the side effects (represented only by itching, slight redness, slight numbness of the treated area, and headaches);

- $\quad$ The need for CE marks for the medical devices used; and

- $\quad$ The need to enroll patients through the inclusion and exclusion criteria.

\subsection{The Trichoscopy Evaluation of the Targeted Area}

Phototrichograms (Figure 4A,B) were taken of all scalps by a trained evaluator using FotoFinder video-epiluminescence microscopy (FotoFinder Systems; http:/ / www. fotofinder.de, accessed on 1 July 2021) in combination with the TrichoScan digital image analysis (Tricholog GmbH and Datinf GmbH; http:/ / trichoscan.com, accessed on 1 July 2021). TrichoScan is a digital software-supported epiluminescence technique for measuring the hair count (the number of hairs per $0.65 \mathrm{~cm}^{2}$ ), hair density (number of hairs per $\mathrm{cm}^{2}$ ), hair diameter, anagen-to-telogen ratio, and vellus hair-to-terminal hair ratio. To determine the quality of hair that led to an increased hair density, it is important to differentiate the number of terminal and vellus hairs. In the TrichoScan analysis, all hairs with a diameter > $40 \mu \mathrm{m}$ were categorized as terminal hairs; those with a lesser diameter were categorized as vellus hairs. In all patients in both the treatment and control half-heads, the two targeted areas (TA) of HL were defined and marked with a semi-permanent tattoo for the subsequent trichogram. In the TA, hairs were clipped and dyed brown for $10 \mathrm{~min}$ to improve the hair contrast for the analytic software. The evaluator of the computerized trichogram analysis was blinded regarding the treatment and control areas of the scalp and was not involved in the administration of the treatment.

\subsection{Statistical Analysis}

HD was expressed as a mean plus or minus the standard deviation (SD). HD differences between the different time points were assessed by a one-way repeated measures analysis of variance (ANOVA); the post-hoc analysis was performed using the Sidak test. All tests were two-tailed and statistical significance was considered as $p<0.05$. All analyses were performed using an online $p$-value calculator (https:/ /www.graphpad.com/ quickcalcs/ttest1.cfm, accessed on 1 July 2021).

\section{Results}

\subsection{Instrumental Evaluation Using Trichoscopy Analysis}

Encouraging results were represented by an HD increase of $12 \pm 2$ hairs $/ \mathrm{cm}^{2}$ at T1 after 16 weeks (16 wks vs. 0 wks) (Figure $4 \mathrm{~B}$ ) in the TA compared with the baseline (Figure $4 \mathrm{~A}$ ). Fifty-nine plus /minus two hairs $/ \mathrm{cm}^{2}$ at T1 versus $47 \pm 2$ hairs $/ \mathrm{cm}^{2}$ at baseline were observed using computerized trichograms, with a statistically significant difference in HR-G ( $p=0.0238)$, while the control area (CA) displayed a mean decrease of 1.1 hairs $/ \mathrm{cm}^{2}$ (control vs. treatment: $p<0.0001$ ). All the details, in terms of HD, have been reported in Table 2. No statistically significant differences in vellus HD among the baseline and T1 have been reported.

No statistically significant differences in HD improvement among Caucasians and Asians at T1 were observed. 
Table 2. In vivo evaluation using trichoscopy analysis in terms of hair density (HD) (hairs $/ \mathrm{cm}^{2}$ ) improvement.

\begin{tabular}{|c|c|c|c|}
\hline Patients & Procedure & $\begin{array}{l}\text { Hair Density } \\
\text { (T0) }\end{array}$ & $\begin{array}{c}\text { Hair Density } \\
\text { (T1-16 wks) }\end{array}$ \\
\hline 1 & $\begin{array}{c}\text { DTSMG MTS stamp + HR3 } \\
\text { matrix }\end{array}$ & $\begin{array}{c}30 \pm 2 \\
\text { hairs } / \mathrm{cm}^{2}\end{array}$ & $\begin{array}{c}42 \pm 2 \\
\text { hairs } / \mathrm{cm}^{2}\end{array}$ \\
\hline 2 & $\begin{array}{c}\text { DTSMG MTS stamp + HR3 } \\
\text { matrix }\end{array}$ & $\begin{array}{c}\quad 44 \pm 2 \\
\text { hairs } / \mathrm{cm}^{2}\end{array}$ & $\begin{array}{c}55 \pm 2 \\
\text { hairs } / \mathrm{cm}^{2}\end{array}$ \\
\hline 3 & $\begin{array}{c}\text { DTSMG MTS stamp }+ \text { HR3 } \\
\text { matrix }\end{array}$ & $\begin{array}{c}59 \pm 2 \\
\text { hairs } / \mathrm{cm}^{2}\end{array}$ & $\begin{array}{c}78 \pm 2 \\
\text { hairs } / \mathrm{cm}^{2}\end{array}$ \\
\hline 4 & $\begin{array}{c}\text { DTSMG MTS stamp }+ \text { HR3 } \\
\text { matrix }\end{array}$ & $\begin{array}{c}36 \pm 2 \\
\text { hairs } / \mathrm{cm}^{2}\end{array}$ & $\begin{array}{c}45 \pm 2 \\
\text { hairs } / \mathrm{cm}^{2}\end{array}$ \\
\hline 5 & $\begin{array}{c}\text { DTSMG MTS stamp }+ \text { HR3 } \\
\text { matrix }\end{array}$ & $\begin{array}{c}75 \pm 2 \\
\text { hairs } / \mathrm{cm}^{2}\end{array}$ & $\begin{array}{c}96 \pm 2 \\
\text { hairs } / \mathrm{cm}^{2}\end{array}$ \\
\hline 6 & $\begin{array}{c}\text { DTSMG MTS stamp }+ \text { HR3 } \\
\text { matrix }\end{array}$ & $\begin{array}{c}43 \pm 2 \\
\text { hairs } / \mathrm{cm}^{2}\end{array}$ & $\begin{array}{c}52 \pm 2 \\
\text { hairs } / \mathrm{cm}^{2}\end{array}$ \\
\hline 7 & $\begin{array}{c}\text { DTSMG MTS stamp }+ \text { HR3 } \\
\text { matrix }\end{array}$ & $\begin{array}{c}76 \pm 2 \\
\text { hairs } / \mathrm{cm}^{2}\end{array}$ & $\begin{array}{c}97 \pm 2 \\
\text { hairs } / \mathrm{cm}^{2}\end{array}$ \\
\hline 8 & $\begin{array}{c}\text { DTSMG MTS stamp }+ \text { HR3 } \\
\text { matrix }\end{array}$ & $\begin{array}{c}52 \pm 2 \\
\text { hairs } / \mathrm{cm}^{2}\end{array}$ & $\begin{array}{c}\quad 60 \pm 2 \\
\text { hairs } / \mathrm{cm}^{2}\end{array}$ \\
\hline 9 & $\begin{array}{c}\text { DTSMG MTS stamp }+ \text { HR3 } \\
\text { matrix }\end{array}$ & $\begin{array}{c}42 \pm 2 \\
\text { hairs } / \mathrm{cm}^{2}\end{array}$ & $\begin{array}{c}\quad 60 \pm 2 \\
\text { hairs } / \mathrm{cm}^{2}\end{array}$ \\
\hline 10 & $\begin{array}{c}\text { DTSMG MTS stamp }+ \text { HR3 } \\
\text { matrix }\end{array}$ & $\begin{array}{c}38 \pm 2 \\
\text { hairs } / \mathrm{cm}^{2}\end{array}$ & $\begin{array}{c}44 \pm 2 \\
\text { hairs } / \mathrm{cm}^{2}\end{array}$ \\
\hline 11 & $\begin{array}{c}\text { DTSMG MTS stamp }+ \text { HR3 } \\
\text { matrix }\end{array}$ & $\begin{array}{c}40 \pm 2 \\
\text { hairs } / \mathrm{cm}^{2}\end{array}$ & $\begin{array}{c}53 \pm 2 \\
\text { hairs } / \mathrm{cm}^{2}\end{array}$ \\
\hline 12 & $\begin{array}{c}\text { DTSMG MTS stamp }+ \text { HR3 } \\
\text { matrix }\end{array}$ & $\begin{array}{c}30 \pm 2 \\
\text { hairs } / \mathrm{cm}^{2}\end{array}$ & $\begin{array}{c}42 \pm 2 \\
\text { hairs } / \mathrm{cm}^{2}\end{array}$ \\
\hline 13 & $\begin{array}{c}\text { DTSMG MTS stamp }+ \text { HR3 } \\
\text { matrix }\end{array}$ & $\begin{array}{c}63 \pm 2 \\
\text { hairs } / \mathrm{cm}^{2}\end{array}$ & $\begin{array}{c}80 \pm 2 \\
\text { hairs } / \mathrm{cm}^{2}\end{array}$ \\
\hline 14 & $\begin{array}{c}\text { DTSMG MTS stamp }+ \text { HR3 } \\
\text { matrix }\end{array}$ & $\begin{array}{c}35 \pm 2 \\
\text { hairs } / \mathrm{cm}^{2}\end{array}$ & $\begin{array}{l}41 \pm 2 \\
\text { hairs } / \mathrm{cm}^{2}\end{array}$ \\
\hline 15 & $\begin{array}{c}\text { DTSMG MTS stamp }+ \text { HR3 } \\
\text { matrix }\end{array}$ & $\begin{array}{c}50 \pm 2 \\
\text { hairs } / \mathrm{cm}^{2}\end{array}$ & $\begin{array}{c}65 \pm 2 \\
\text { hairs } / \mathrm{cm}^{2}\end{array}$ \\
\hline 16 & $\begin{array}{c}\text { DTSMG MTS stamp }+ \text { HR3 } \\
\text { matrix }\end{array}$ & $\begin{array}{c}\quad 40 \pm 2 \\
\text { hairs } / \mathrm{cm}^{2}\end{array}$ & $\begin{array}{l}\quad 44 \pm 2 \\
\text { hairs } / \mathrm{cm}^{2}\end{array}$ \\
\hline 17 & $\begin{array}{c}\text { DTSMG MTS stamp }+ \text { HR3 } \\
\text { matrix }\end{array}$ & $\begin{array}{c}65 \pm 2 \\
\text { hairs } / \mathrm{cm}^{2}\end{array}$ & $\begin{array}{c}78 \pm 2 \\
\text { hairs } / \mathrm{cm}^{2}\end{array}$ \\
\hline 18 & $\begin{array}{c}\text { DTSMG MTS stamp }+ \text { HR3 } \\
\text { matrix }\end{array}$ & $\begin{array}{c}33 \pm 2 \\
\text { hairs } / \mathrm{cm}^{2}\end{array}$ & $\begin{array}{c}38 \pm 2 \\
\text { hairs } / \mathrm{cm}^{2}\end{array}$ \\
\hline 19 & $\begin{array}{c}\text { DTSMG MTS stamp }+ \text { HR3 } \\
\text { matrix }\end{array}$ & $\begin{array}{c}56 \pm 2 \\
\text { hairs } / \mathrm{cm}^{2}\end{array}$ & $\begin{array}{c}65 \pm 2 \\
\text { hairs } / \mathrm{cm}^{2}\end{array}$ \\
\hline 20 & $\begin{array}{c}\text { DTSMG MTS stamp }+ \text { HR3 } \\
\text { matrix }\end{array}$ & $\begin{array}{c}45 \pm 2 \\
\text { hairs } / \mathrm{cm}^{2}\end{array}$ & $\begin{array}{c}57 \pm 2 \\
\text { hairs } / \mathrm{cm}^{2}\end{array}$ \\
\hline
\end{tabular}

\subsection{Clinical Evaluation}

Regarding the investigator evaluation, scores ranged from 2 to $5(p=0.123)$, and 14 patients $(70 \%)$ (8 males and 6 females), who underwent the LLLT reported good results regarding global scalp coverage and hair thickness (Figures 2B, 3B, and $5 \mathrm{~B}$ ) versus 6 patients $(30 \%)$ ( 2 males and 4 females) with ineffective results. 
Regarding the patient evaluation, scores ranged from 1 to $4(p=0.031)$, and 17 patients ( $85 \%$ ) (9 males and 8 females) indicated a good level of satisfaction regarding the global scalp coverage, versus only 3 patients (15\%) (1 male and 2 females) who indicated ineffective results.

The results reported show male patients as more satisfied than female patients. A satisfaction grade assessment questionnaire analysis showed that all people (Caucasian and Asian) would choose to undergo hair biostimulation with LLLT and they were sufficiently informed about the risks and side effects of this treatment (including the high possibility of repeating the treatment multiple times).

\section{Discussion}

Several studies have investigated different low-level laser and light sources with related treatment parameters for the management of alopecia, like LLLT [19-24], various wavelengths of LED light $[25,26]$, and several other techniques that are combined, such as LED-LLLT [27]. Although the available literature regarding phototherapy-based devices to treat AGA is restricted, the study results regarding the outcomes showed a more robust performance than those reported in previous studies.

Leavitt et al. (2009) [27] conducted a 26-week, randomized, double-blind, devicecontrolled, multicenter trial during which 110 male patients with AGA IIa-V were randomized for treatment with the HairMax LaserComb ${ }^{\circledR}$ [27]. The primary efficacy endpoint was the mean terminal HD. At 26 weeks, HD had an average increase of $19.8 \%$ in the patients of the study group. Kim et al. (2013) [20] performed a randomized, double-blind, sham device-controlled trial at two research centers that included 40 male and female subjects with AGA treated with a helmet-type 3R LLLT device, with a lightweight source consisting of LEDs emitting wavelengths of $630 \mathrm{~nm}(3.5 \mathrm{~mW}, 24$ units, L-513ECA) and $660 \mathrm{~nm}$ (2.5 mW, 18 units, L-513LRC) and an LD with wavelengths of $650 \mathrm{~nm}(4 \mathrm{~mW}, 27$ units, DL3147-060) [20]. The primary efficacy endpoint was HD after 24 weeks of treatment estimated with trichograms. Six months after the last procedure, the mean percentage of the increase in HD was 14.7\%. Finally, Suchonwanit et al. (2018) [28] conducted a 24-week, prospective, randomized, double-blind, device-controlled run that included male subjects aged over 18 years with AGA that were treated with RAMACAP, a combat helmet-shaped device containing single-mode LDs which emitted a wavelength of $660 \pm 10 \mathrm{~nm}$ [28]. The first efficacy endpoint was HD and the hair diameter in the TA at weeks 8, 16, and 24, by photographing the TA with a Folliscope ${ }^{\circledR}$ and measuring it with Folliscope 2.8 software (LeadM Corporation, Seoul, Korea). Six months after treatment, the mean percentage of an increase in $\mathrm{HD}$ was $9.1 \%$.

However, there was a significant difference between light and laser sources. Thirtytwo home-use LLLT devices cleared by the US-FDA were found and analyzed in the literature through several studies, including seven randomized clinical trials (RCTs) (such as 1 Capillus ${ }^{\circledR}$ [29], 2 HairMax ${ }^{\circledR}$ [27], 2 iGrow $^{\circledR}$ [30-32], and 2 iRestore ${ }^{\circledR}$ [33,34]), and two cohort studies (one perspective [35] and one retrospective [36]) to support the efficacies of home-use LLLT devices.

The subjects in most of the RCTs had mild to moderate patterned hair loss, MPHL (NW grade IIa-V) and/or FPHL (LW-Savin Baldness Scale I-2, I-3, I-4, II-1, and II-2). The duration of studies ranged from 16 to 26 weeks, with a mean duration of 21.3 weeks. For the assessment, most RCTs showed positive results of an increase in microscopic hair counts. The majority of the LLLT treatment groups yielded a statistically significant improvement in hair counts compared to the control group. In two non-controlled trials [35,36], LLLT also demonstrated an improvement when compared to baseline, with no provided $p$-value. Meanwhile, there was one RCT that also studied the effectiveness of a helmet LLLT device in combination with topical minoxidil in FPHL [37]. The application protocol differences of LLLT devices included the shape, light source, number of LEDs and LDs, the wavelength, and the total power output. Due to no head-to-head study to evaluate the devices, the clinical benefits of one over the other cannot be determined. When considering the number 
of diodes, the comb-type LLLT devices used the least number of diodes, ranging from 7 to 12 diodes. Besides, the prices of the comb-type LLLT devices were cheaper than other shapes and proved clinical effectiveness [31]. Therefore, they could be good options for patients with financial limitations. Additionally, the hands-free devices, including caps [29] and helmets [30,32,37], which have proven clinical effectiveness, usually used a high number of diodes ranging from 40 to 304 diodes with user-friendly capabilities. Patients could manage their daily activities during treatment sessions. Among 32 home-use LLLT devices, the majority ( $87.5 \%$ ) of them were composed of only one LD, with essential lasers for therapeutic benefits. Following the collimated, coherent, highly monochromatic beam properties, the possibility of high-power densities was then considered preferable [38]. Interestingly, this systematic review revealed a significant difference between light and laser sources. However, the non-coherent light sources, such as LEDs and broad-band lamps, have recently become common with the advantages of LED, including no laser safety considerations, the ease of home use, the ability to irradiate a large area of tissue at once, the possibility of a wearable device, and the much lower cost per $\mathrm{mW}$. A range of light energy sources, from LEDs to lasers, have been used with specific advantages and limitations [39]. Currently, there is evidence to show the non-dependence of photobiomodulation on lasers or coherence. However, the monochromatic LED devices could also yield physiological effects [38]. The study of LLLT devices for MPHL and FPHL treatments consisted of 224 red LDs $(660 \mathrm{~nm}, 5 \mathrm{~mW})$ for the treatment group, while the sham devices were composed of $224 \operatorname{LED}(650+20 \mathrm{~nm})$ for the control group. Each LD had optical power at the irradiance of $3.5 \mathrm{~mW} / \mathrm{cm}^{2}$, whereas LEDs had the power of $0.5 \mathrm{~mW} /$ diode (ten times lower than LD). The results of the study yielded an increase in HD and in hair diameter in both groups. The treatment group was significantly superior to the sham devices. The mean change from baseline to week 24 for HD was $10.21 \pm 3.25$ hairs $/ \mathrm{cm}^{2}$ in the treatment group, versus $3.95 \pm 1.32$ hairs $/ \mathrm{cm}^{2}$ in the sham group. The mean change for the hair diameter was $6.11 \pm 2.15 \mu \mathrm{m}$ in the laser group versus $3.76 \pm 1.24 \mu \mathrm{m}$ in the sham group. Therefore, the LEDs seemed to influence photo-biomodulation, as well as the LDs. Due to the very low power of LEDs used in this study ( $0.5 \mathrm{~mW} /$ diode), when compared to the appropriate dose of $2-4 \mathrm{~J} / \mathrm{cm}^{2}$, the results of LEDs in this study could not be concluded [28]. Nevertheless, some head-to-head studies that compared both light sources showed no difference in their effects [37]. Hence, more high-quality head-to-head comparison studies are recommended to verify the significant differences between dose responses and the physiological effects of LEDs and laser PBMs [37,39]. When considering the wavelength, all devices used the light/laser sources with 620-678 nm due to the absorption peak at $660 \mathrm{~nm}$ [40], with CCO as the chromophore for LLLT. According to the Arndt-Schulz Law, as reported in the article of Huang et al. [41], it is widely accepted that if the irradiance or the duration is too short, there is no response. Similarly, if the irradiance or duration is too high, then the response may be instead inhibited. According to Huang et al. [41], the irradiance of $2-4 \mathrm{~J} / \mathrm{cm}^{2}$ was suspected to be appropriate. When this theory was applied to the LLLT devices, it usually provided patients with therapeutic irradiance. From the published articles that support the effectiveness of the devices, it is obvious that the included participants had only mild to moderate MPHL and/or FPHL.

However, no study has been conducted for severe cases of HL. In a study that compared the effectiveness of standard treatments, including oral finasteride and topical minoxidil with LLLT, $1 \mathrm{mg}$ of Finasteride ${ }^{\circledR}$ in MPHL for 12 months significantly increased the total hair counts by $7.3 \%$ and $8.99 \%$ at 6 and 12 months, respectively $(p<0.001)$ [42], whereas $2 \%$ and $5 \%$ topical Minoxidil ${ }^{\circledR}$ demonstrated a significant increase in non-vellus hair counts of $8.84 \%(p=0.013)$ and $12.3 \%(p<0.001)$ at 48 weeks, respectively [43]. The LLLT effectiveness revealed a significant increase in terminal hair counts of $20.9(12.79 \%$, $p=0.0249)$ vs. $25.7 / \mathrm{cm}^{2}(16.96 \%, p=0.0028)$ in the 9 - and 12 -beam laser comb treated areas at 26 weeks after treatment, respectively [31]. Hence, the effectiveness of LLLT appeared to be comparable to the conventional hair loss treatments. Moreover, comparable effectiveness was also observed in the treatment of FPHL for four months. Furthermore, the combination 
of the treatment of $5 \%$ Minoxidil $^{\circledR}$ and LLTT seemed to provide a better response on HD than Minoxidil ${ }^{\circledR}$ or LLLT alone [37]. A literature analysis demonstrated the relative effectiveness and safety of LLLT in the treatment of MPHL and/or FPHL from the analysis of RCTs, offering another new effective treatment method for HL. In the author's opinion, the need for large-scale RCTs and more systematic reviews appears necessary to confirm the effectiveness of LLLT, which is currently suffering from considerable applicative protocol heterogeneity. The heterogeneity is mainly because of the different treatment regimens represented by the LED or LD number, device shape, and kind (cap, comb, hairband, or helmet), wavelength, the power adopted, and the duration times. For the above-mentioned reasons, currently a widely shared protocol of LLLT application is lacking.

\section{Conclusions}

This case-series study showed the effectiveness of LLLT in mild to moderate MPHL (AGA I-III sec. Norwood-Hamilton) and FPHL (AGA I sec. Ludwig) through clinical and trichoscopy analyses without any side effects. For these reasons, LLLT therapy may be considered a safe procedure, but for the moment, it is effective only in treating a low degree of AGA.

Author Contributions: P.G. was the leader and principal author of this paper, performing the methodology, conceptualization, formal analysis, validation, investigation, data curation, writingoriginal draft preparation, writing-review and editing, acquisition funding and resources and project administration; S.-I.L., S.H., and S.G. contributed resources and were involved in data curation, analysis, and visualization; S.-I.L., S.H. have contributed with clinical cases, data curation, analysis, and validation. All authors have read and agreed to the published version of the manuscript.

Funding: This work was supported by Kyungnam University Foundation Grant, 2020.

Institutional Review Board Statement: This paper has been the object of a research contract between the author P.G. and the “Tor Vergata" University, approved by Rectoral Decree R.D n. \#1467/2017, continued in associate professor contract \#13489/2021.

Informed Consent Statement: Informed consent was obtained from all subjects involved in the study.

Acknowledgments: The authors would like to acknowledge all parties that participated in this study. This work has been written totally by Pietro Gentile, independent mind, exclusively based on scientific and clinical results obtained.

Conflicts of Interest: The authors declare no conflict of interest.

\section{References}

1. Alsantali, A.; Shapiro, J. Androgens and hair loss. Curr. Opin. Endocrinol. Diabetes Obes. 2009, 16, 246-253. [CrossRef] [PubMed]

2. Price, V.H. Treatment of hair loss. N. Engl. J. Med. 1999, 341, 964-973. [CrossRef] [PubMed]

3. Gentile, P.; Garcovich, S.; Bielli, A.; Scioli, M.G.; Orlandi, A.; Cervelli, V. The effect of platelet-rich plasma in hair regrowth: A randomized placebo-controlled trial. Stem Cells Transl. Med. 2015, 4, 1317-1323. [CrossRef]

4. Gentile, P.; Cole, J.P.; Cole, M.A.; Garcovich, S.; Bielli, A.; Scioli, M.G.; Orlandi, A.; Insalaco, C.; Cervelli, V. Evaluation of Not-Activated and Activated PRP in Hair Loss Treatment: Role of Growth Factor and Cytokine Concentrations Obtained by Different Collection Systems. Int. J. Mol. Sci. 2017, 18, 408. [CrossRef] [PubMed]

5. Mester, E.; Szende, B.; Tota, J. Effect of laser on hair growth of mice. Kiserl Orv. 1967, 19, 628-631.

6. Hamblin, M.R. Photobiomodulation for the management of alopecia: Mechanisms of action, patient selection, and perspectives. Clin. Cosmet. Investig. Derm. 2019, 12, 669. [CrossRef]

7. Wikramanayake, T.C.; Rodriguez, R.; Choudhary, S.; Mauro, L.M.; Nouri, K.; Schachner, L.A.; Jimenez, J.J. Effects of the Lexington LaserComb on hair regrowth in the $\mathrm{C} 3 \mathrm{H} / \mathrm{HeJ}$ mouse model of alopecia areata. Lasers Med. Sci. 2012, 27, 431-436. [CrossRef]

8. Kim, W.S.; Calderhead, R.G. Is light-emitting diode phototherapy (LED-LLLT) effective? Laser Ther. 2011, 20, 205-215. [CrossRef] [PubMed]

9. Avci, P.; Gupta, G.K.; Clark, J.; Wikonkal, N.; Hamblin, M.R. Low-Level Laser (Light) Therapy (LLLT) for Treatment of Hair Loss. Lasers Surg. Med. 2013, 46, 144-151. [CrossRef]

10. Suchonwanit, P.; Rojhirunsakool, S.; Khunkhet, S. A randomized, investigator-blinded, controlled, split-scalp study of the efficacy and safety of a 1550-nm fractional erbium-glass laser, used in combination with topical $5 \%$ minoxidil versus $5 \%$ minoxidil alone, for the treatment of androgenetic alopecia. Lasers Med. Sci. 2019, 34, 1857-1864. [CrossRef] 
11. Ash, C.; Harrison, A.; Drew, S.; Whittall, R. A randomized controlled study for the treatment of acne vulgaris using high-intensity $414 \mathrm{~nm}$ solid-state diode arrays. J. Cosmet Laser Ther. 2015, 4, 170-176. [CrossRef]

12. Naranjo García, P.; Elias, J.A.; Gaviria Parada, J.; Zarza Luciañez, D.; Pinto, H.R. Management of Vaginal Atrophy with Intravaginal Light-Emitting Diodes (LEDs). Int J. Obstet. Gyanecol. Res. 2018, 5, 632-641.

13. Calderhead, R.G.; Vasily, D.B. Low-Level Light Therapy with Light-Emitting Diodes for the Aging Face. Clin. Plast. Surg. 2016, 43, 541-550. [CrossRef] [PubMed]

14. Weiss, R.A.; McDaniel, D.H.; Geronemus, R.G.; Weiss, M.A. Clinical trial of a novel non-thermal LED array for reversal of photoaging: Clinical, histologic, and surface profilometric results. Lasers Surg. Med. 2005, 36, 85-91. [CrossRef]

15. Yang, K.; Tang, Y.; Ma, Y.; Liu, Q.; Huang, Y.; Zhang, Y.; Shi, X.; Zhang, L.; Zhang, Y.; Wang, J.; et al. Hair Growth Promoting Effects of $650 \mathrm{~nm}$ Red Light Stimulation on Human Hair Follicles and Study of Its Mechanisms via RNA Sequencing Transcriptome Analysis. Ann. Dermatol. 2021, 33, 553-561. [CrossRef] [PubMed]

16. Gentile, P.; Dionisi, L.; Pizzicannella, J.; de Angelis, B.; de Fazio, D.; Garcovich, S. A randomized blinded retrospective study: The combined use of micro-needling technique, low-level laser therapy, and autologous non-activated platelet-rich plasma improves hair re-growth in patients with androgenic alopecia. Exp. Opin. Biol. Ther. 2020, 20, 1099-1109. [CrossRef]

17. Schuklenk, U.; Ashcroft, R. International research ethics. Bioethics 2000, 14, 158-172. [CrossRef]

18. Von Elm, E.; Altman, D.G.; Egger, M.; Pocock, S.J.; Gøtzsche, P.C.; Vandenbroucke, J.P.; STROBE Initiative. The Strengthening the Reporting of Observational Studies in Epidemiology (STROBE) statement: Guidelines for reporting observational studies. J. Clin. Epidemiol. 2008, 61, 344-349. [CrossRef]

19. Gentile, P.; Garcovich, S. The Effectiveness of Low-Level Light/Laser Therapy on Hair Loss. Facial. Plast. Surg. Aesthet. Med. 2021. [CrossRef]

20. Mahe, Y.F.; Cheniti, A.; Tacheau, C.; Antonelli, R.; Planard-Luong, L.; de Bernard, S.; Buffat, L.; Barbarat, P.; Kanoun-Copy, L. Low-Level Light Therapy Downregulates Scalp Inflammatory Biomarkers in Men With Androgenetic Alopecia and Boosts Minoxidil 2\% to Bring a Sustainable Hair Regrowth Activity. Lasers Surg. Med. 2021, 53, 1208-1219. [CrossRef]

21. Darwin, E.; Heyes, A.; Hirt, P.A.; Wikramanayake, T.C.; Jimenez, J.J. Low-level laser therapy for the treatment of androgenic alopecia: A review. Lasers Med. Sci. 2018, 21, 425-434. [CrossRef]

22. Barikbin, B.; Khodamrdi, Z.; Kholoosi, L.; Akhgri, M.R.; Abbasi, M.H.; Hajabbasi, M.; Razzaghi, Z.; Akbarpour, S. Comparison of the effects of $665 \mathrm{~nm}$ low-level diode Laser Hat versus and a combination of $665 \mathrm{~nm}$ and 808nm low-level diode Laser Scanner of hair growth in androgenic alopecia. J. Cosmet. Laser Ther. 2017, 17. [CrossRef]

23. Afifi, L.; Maranda, E.L.; Zarei, M.; Delcanto, G.M.; Falto-Aizpurua, L.; Kluijfhout, W.P.; Jimenez, J.J. Low-level laser therapy as a treatment for androgenetic alopecia. Lasers Surg. Med. 2017, 49, 27-39. [CrossRef]

24. Avram, M.R.; Rogers, N.E. The use of low-level light for hair growth: Part I. J. Cosmet Laser Ther. 2009, 12, 110-117. [CrossRef] [PubMed]

25. Joo, H.J.; Jeong, K.H.; Kim, J.E.; Kang, H. Various Wavelengths of Light-Emitting Diode Light Regulate the Proliferation of Human Dermal Papilla Cells and Hair Follicles via Wnt/B-Catenin and the Extracellular Signal-Regulated Kinase Pathways. Ann. Dermatol. 2017, 29, 747. [CrossRef] [PubMed]

26. Sorbellini, E.; Rucco, M.; Rinaldi, F. Photodynamic and photobiological effects of light-emitting diode (LED) therapy in dermatological disease: An update. Lasers Med. Sci. 2018, 33, 1431-1439. [CrossRef]

27. Leavitt, M.; Charles, G.; Heyman, E.; Michaels, D. HairMax LaserComb ${ }^{\circledR}$ laser phototherapy device in the treatment of male androgenetic alopecia: A randomized, double-blind, sham device-controlled, multicentre trial. Clin. Drug Investig. 2009, 29, 283-292. [CrossRef] [PubMed]

28. Suchonwanit, P.; Chalermroj, N.; Khunkhet, S. Low-level laser therapy for the treatment of androgenetic alopecia in Thai men and women: A 24-week, randomized, double-blind, sham device-controlled trial. Lasers Med. Sci. 2018, 19, 1107-1114. [CrossRef]

29. Friedman, S.; Schnoor, P. Novel approach to treating androgenetic alopecia in females with photobiomodulation (low-level laser therapy). Derm. Surg. 2017, 43, 856-867. [CrossRef] [PubMed]

30. Lanzafame, R.J.; Blanche, R.R.; Chiacchierini, R.P.; Kazmirek, E.R.; Sklar, J.A. The growth of human scalp hair in females using visible red-light laser and LED sources. Lasers Surg. Med. 2014, 46, 601-607. [CrossRef]

31. Jimenez, J.J.; Wikramanayake, T.C.; Bergfeld, W.; Hordinsky, M.; Hickman, J.G.; Hamblin, M.R.; Schachner, L.A. Efficacy and safety of a low-level laser device in the treatment of male and female pattern hair loss: A multicenter, randomized, sham device-controlled, double-blind study. Am. J. Clin. Dermatol. 2014, 15, 115-127. [CrossRef]

32. Lanzafame, R.J.; Blanche, R.R.; Bodian, A.B.; Chiacchierini, R.P.; Fernandez-Obregon, A.; Kazmirek, E.R. The growth of human scalp hair mediated by visible red-light laser and LED sources in males. Lasers Surg. Med. 2013, 45, 487-495. [CrossRef] [PubMed]

33. Kim, H.; Choi, J.W.; Kim, J.Y.; Shin, J.W.; Lee, S.-J.; Huh, C.-H. Low-level light therapy for androgenetic alopecia: A 24-week, randomized, double-blind, sham device-controlled multicenter trial. Derm. Surg. 2013, 39, 1177-1183. [CrossRef]

34. Fan, S.M.-Y.; Cheng, Y.-P.; Lee, M.-Y.; Lin, S.-J.; Chiu, H.-Y. Efficacy and Safety of a Low-Level Light Therapy for Androgenetic Alopecia: A 24-Week, Randomized, Double-Blind, Self-Comparison, Sham Device-Controlled Trial. Derm. Surg. 2018, 44, 1411-1420. [CrossRef] [PubMed]

35. Satino, J.L.; Markou, M. Hair regrowth and increased hair tensile strength using the HairMax LaserComb for low-level laser therapy. Int J. Cosmet Surg. Aesthetic Dermatol. 2003, 5, 113-117. [CrossRef] 
36. Munck, A.; Gavazzoni, M.F.; Trüeb, R.M. Use of low-level laser therapy as monotherapy or concomitant therapy for male and female androgenetic alopecia. Int. J. Trichology 2014, 6, 45.

37. Esmat, S.M.; Hegazy, R.A.; Gawdat, H.I.; Hay, R.A.; Allam, R.; El Naggar, R.; Moneib, H. Low-level light-minoxidil 5\% combination versus either therapeutic modality alone in the management of female patterned hair loss: A randomized controlled study. Lasers Surg. Med. 2017, 49, 835-843. [CrossRef] [PubMed]

38. Heiskanen, V.; Hamblin, M.R. Photobiomodulation: Lasers vs. light-emitting diodes? Photochem. Photobiol. Sci. 2018, 17, 1003-1017. [CrossRef]

39. Mosca, R.C.; Ong, A.; Albasha, O.; Bass, K.; Arany, P. Photobiomodulation Therapy for Wound Care: A Potent, Noninvasive, Photoceutical Approach. Adv. Ski. Wound Care 2019, 32, 157-167. [CrossRef] [PubMed]

40. Karu, T.I.; Kalendo, G.S.; Letokhov, V.S.; Lobko, V.V. Biostimulation of HeLa cells by low-intensity visible light. Il Nuovo Cim. D 1982, 1, 828-840. [CrossRef]

41. Huang, Y.; Chen, A.C.-H.; Carroll, J.D.; Hamblin, M.R. Biphasic dose response in low-level light therapy. Dose-Response 2009, 7 , 9-27. [CrossRef] [PubMed]

42. Roberts, J.L.; Fiedler, V.; Imperato-McGinley, J.; Whiting, D.; Olsen, E.; Shupack, J.; Stough, D.; DeVillez, R.; Rietschel, R.; Savin, R.; et al. Clinical dose-ranging studies with finasteride, a type $25 \alpha$-reductase inhibitor, in men with male pattern hair loss. J. Am. Acad. Derm. 1999, 41, 555-563. [PubMed]

43. Olsen, E.A.; Dunlap, F.E.; Funicella, T.; Koperski, J.A.; Swinehart, J.M.; Tschen, E.H.; Trancik, R.J. A randomized clinical trial of 5\% topical minoxidil versus $2 \%$ topical minoxidil and placebo in the treatment of androgenetic alopecia in men. J. Am. Acad. Derm. 2002, 47, 377-385. [CrossRef] [PubMed] 